the detriment of the child. Instruction so given is rarely permanent and when lasting only serves to make the child ashamed, disgusted, and intolerant of his home.

The teaching of table manners is important and every child should be taught them, but the home and not the school is the place for such instruction. A very few parents resent this usurpation of their prerogatives by the school; some parents are indifferent; but far too many are only too glad thus to shirk the responsibility that is really theirs. Parents tend to become even further demoralized and perhaps pauperized when experience discloses the lamentable fact that in many instanes a free meal constitutes the greatest inducement that influences them to send their child to an open-air school.

It would seem, then, that the open-air school is not the last word. Conceived with but a single object in view, instituted with impulsive enthusiasm, and developed not step by step, but at a single bound, its possible consequences along lines other than hygienic were not foreseen. Moreover, even from a hygienic standpoint, experience with the innovation has brought forth something of a shock, for it has not proved to be the panacea for the physical ills of school children that was confidently hoped for. Certain children have not only failed to derive benefit from it, but have even suffered harm; and its application has had to be restricted. Sober, second thought has disclosed that the failure to regard possible consequences of the innovation along lines other than hygienic has been disastrous for its continuance as a valuable public institution. From an economic standpoint the open-air school is a poor investment; from an educational point of view it is a step backward; and from a moral standpoint it is unwise.

It would seem necessary, therefore, to recede a bit from the perilously advanced position that has been taken, and the next step backward is the open-window schoolroom. Its hygienic value is an accepted fact; economically it demands a minimum expense and affords equal advantages for all; educationally it keeps step with progress ; and morally it has nothing to condemn it.

\section{CONTROL OF THE CARELESS AND INCORRIGIBLE CONSUMPTIVE.*}

BY C. T. CALLAHAN, ESQ., HOLYOKE:

District Attorney, Western District, Holyoke, Mass.

THE discovery by the medical profession that tuberculosis is a communicable disease and that, to prevent the spread of the scourge, some control of the movements and conduct of persons afflicted with the disease is necessary gives rise to the very important question as to how far the

* Read at the Massachusetts Conference on Tuberculosis, Holyoke Mass., March 22, 1913.
State may invade the personal liberty of the individual in the attainment of its object. My treatment of the subject, "The Control of the Careless and Incorrigible Consumptive," will be that of a lawyer addressing himself to a consideration of the rights of the public on the one hand and of the patient on the other. Whether tuberculosis is a disease which can be cured, whether the danger of infection is so great as to threaten the whole community, and whether treatment of the disease in isolation may reasonably be expected to exterminate it are questions peculiarly for the determination in the first instance of the medical profession. If we except certain phases of the subject of insanity, it may be said that the law has always given profound respect to medical opinion. Thus, if the doctors should agree that tuberculosis was a communicable disease, menacing to the public health and that it could be appreciably controlled by isolation, their conclusion would be accepted by the courts as a fact of common knowledge and would be a strong element in their consideration of the extent of the powers of the State to suppress the disease.

Assuming the propositions advanced in favor of physical restraint to be established, how far can the State undertake to control the careless and incorrigible consumptive? In the last two centuries society has constantly enlarged its right to restrain persons afflicted with disease as a matter of self-protection. By the common law of England, the only remedy for the suppression of sources of disease was an action for damages or an indictment for nuisance. As medical investigation of public health probed deeper and deeper into the cause of disease, the law responded to the demands of the profession for corrective measures, and the enactment of such legislation has repeatedly raised the question how far the personal rights of the victim may be invaded in the interests of the common good. A few broad considerations lie at the foundation of all consideration and all discussion of the subject. It has always been held that, with birth itself, citizens are endowed with the right to enjoy life, liberty and property. But man has a right to natural freedom only in so far as the exercise of it is not inconsistent with the rights of others. The limitation is clearly stated in the preamble of our own bill of rights: "The body politic. . . is a social compact by which the whole people covenants with each citizen, and each eitizen with the whole people, that all shall be governed by certain laws for the common good." In connection with this should be read the constitutional provision creating the right of men to enjoy and defend their lives and liberties, and the article granting full power and authority to the General Court to enact "all manner of wholesome and reasonable orders, laws, statutes, ordinances, directions and instructions. . . as they shall judge to be for the good and welfare of this Commonwealth."

The exercise of the police power thus con- 
ferred on the Legislature has seldom been interfered with by the courts. In the phrase "wholesome and reasonable orders" and so forth, there would seem to be reserved to the courts a power to review and set aside an act of the Legislature relating to the public health which might unduly invade the personal liberties of citizens. But, as a rule, the courts have hesitated to place limits upon the legislative exercise of the police power. It has been held that it extends generally to the protection and preservation of the public health on the principle that the rights of individuals must give way to the community welfare. It has been held to be true of the right to personal liberty as well as the right to property. The power to hold persons in quarantine has been upheld. It has been clearly settled in this Commonwealth that "a man afflicted with the smallpox, or any other contagious disease dangerous to public health, has for the time being lost his right to personal freedom, and may be compelled to yield to restraint, carried, if necessary, even to compulsory isolation." So, that the public officers, in their discretion, might even remove to a hospital the person fallen ill, or care for him in the house in which he resided. On the general principle that individual right must yield to public right, it has been held that a person suffering loss of rents from the location of a properly conducted hospital in his neighborhood, has no remedy. The statute authorizing boards of health to require the vaccination of all the inhabitants, and imposing a fine for a violation of such requirement, was held constitutional in this State, and this decision was affirmed by the Supreme Court of the United States.

But decisions of this kind in this State appear to be limited to cases of smallpox or other virulent epidemics. That may be, and probably is, due to the fact that boards of health have been reluctant to exercise the powers conferred on them by the Legislature.

Before 1906 the statutes authorized boards of health, if a disease dangerous to public health broke out, or if a person was infected, to provide immediately a hospital or place of reception, and to cause any sick or infected person to be removed to it if it could be done without danger to his health, in which last event the house or place where the sick person was could be considered as a hospital, and the people living in the house could be subjected to the regulations of the board, and, if necessary, persons in the neighborhood might be required to move away. This power could be enforced by a warrant of the courts directed to a sheriff, or his deputies, or to any constable or police officer, requiring them, under the supervision of the board, to remove such person or "to impress and take up convenient houses, lodging, nurses, attendants and other necessaries." However, it was provided that these powers should not apply to smallpox except in cases of persons residing in boardinghouses or hotels, or in cases of two or more fami- lies occupying the same dwelling, or in other cases in which, in the opinion of the board and the attending physician, the case could not be properly isolated. In 1906, in addition to other amendments not necessarily material to this discussion, this statute was amended so that the power of removal of patients from their homes is no longer limited as to cases of smallpox, but appears to be restricted as to all diseases dangerous to the public health. It would appear, therefore, that even now the authority of removal in all cases is limited to boarding-houses or hotels or to dwellings occupied by two or more families, unless, in the opinion of the board, the case cannot be properly isolated. The opinion of the attending physician is eliminated as a factor in determining whether the case can or cannot be isolated, and, in all probability, the opinion of the board formed in good faith would be held conclusive in a case where the sick person was not living in a hotel, boarding-house or tenement building. By a later statute passed in 1907, the State Board of Health was authorized and directed to define what diseases shall be deemed to be dangerous to public health. I am informed that the State Board, in pursuance of this duty, has declared tuberculosis to be such a disease. Last year the Legislature recognized it in precise terms as a disease dangerous to the public health, in Chapter 151, amending Section 35 of Chapter 75 of the Revised Laws, relating to the establishment and maintenance of hospitals in cities and towns. In the amendment these institutions are described as "hospitals for the reception of persons having smallpox, diphtheria, scarlet fever, tuberculosis or other diseases dangerous to the public health as defined by the State Board of Health.",

If we assume that in the statutes mentioned the Legislature has clearly expressed its intention to confer upon Boards of Health the power to enforce involuntary isolation in cases of tuberculosis, will the Supreme Judicial Court uphold the constitutionality of the Legislature's exercise of its police power in this particular kind of disease? The question ought to be put to that tribunal purely on its merits, and ought not to be complicated by unnecessary technicalities. It would be good preliminary tactics to codify all the statutes relating to public health, so there would be no possible question raised of the Legislature's meaning to bring cases of consumption within the power of boards to compel involuntary isolation.

Thus presented, the one issue for the court would be the constitutionality of the law. There can be little doubt that involuntary isolation will be resisted by many persons suffering from this disease. The issue presents some important and interesting considerations. It will be observed that the cases in which the exercise of the police power in the suppression of disease dangerous to the public health has been upheld, the courts had to deal with diseases vastly different in their nature, their infectiousness and their duration. 
For example, in dealing with smallpox cases, it was indisputable that the disease spread rapidly, threatening entire communities, that isolation was necessary to its prevention, and, more important than all to the question before us, that, owing to the usual course of the disease, compulsory isolation was comparatively brief and meant no more to the patient, if he survived, than a temporary restraint of his personal liberty. I assume in favor of the medical profession that it would have no difficulty in establishing as facts in the case that tuberculosis is infectious and that isolation would tend to suppress it. But the issue presented, the invasion of personal liberty, guaranteed by all constitutions and by all law, is of such tremendous importance to the individual that I cannot conceive of a refusal by the court to receive evidence upon the question whether the law is "wholesome and reasonable" within the meaning of the constitution. Upon this question it is of prime importance to bear in mind that in the present state of medical treatment the curability of tuberculosis is at least in grave doubt. Unlike smallpox, diphtheria and scarlet fever, tuberculosis is not a disease of short duration. To isolate in some stages of it would mean a denial of personal liberty for life. Is the infectiousness of the disease of such a character that to allow unlimited personal liberty to its victims constitutes a real danger to public health? Would you be sure of your ground in maintaining that it assumed the character of an epidemic, as in the other diseases mentioned? If these questions can be answered affirmatively, would the court say that a law under which a sufferer might be deprived of his personal liberty for the rest of his days was "wholesome and reasonable"? To illustrate, it would be difficult to maintain that the application of such a law to cases of diabetes or pneumonia, for example, would be held "wholesome and reasonable." On the other hand, the peculiar disease under discussion, which enables its victim to walk about almost to his last hours, compelling him by its very agonies to cough into the air and to spit out, wherever he may be, germs that may prostrate others, would seem to fortify the demand of the doctors for power to control the movements of such agents of death. Whether authority to isolate, with its attendant restriction of liberty, severance of family relations and consequences to property rights, will be upheld by our highest court, I do not undertake to say.

However, it may at least be said that the contentions of the profession are entitled to the highest respect. A demand, fortified by so strong authority, should be passed upon as soon as possible for the common welfare. As citizens desiring the passage of "wholesome and reasonable" laws, we should all be anxious for the speedy determination of a question involving such tremendous consequences to mankind. As a lawyer, I shall be keenly interested in the court's treatment of it. By all means, press the issue. Ask for a codification of the statutes bear- ing on the subject. Proceed under them, and let the Supreme Judicial Court say the word which shall mean that the carrier of this disease may be isolated in the interests of the general welfare, or that the medical profession must define new rules, with penalties attached, for legislative sanction for the regulation of their conduct while at liberty.

\section{ON THE FREQUENCY OF THE TRANSI- TION OF ULCER OF THE STOMACH INTO CANCER.*}

BY JULIUS FRIEDENWALD, M.D., BaLtimore,

Professor of Gastro-Enterology, College of Physicians and Surgeons, Baltimore, $M d$.

Much interest has been manifested in recent years, regarding the frequency of the development of cancer of the stomach upon the scar of an old ulcer.

Among the earlier writers, Cruveilhier (1839) and Dittrich (1848) were among the first to point to this condition, while Zenker in 1882 maintained that all cases of cancer of the stomach had their origin in simple ulcer. Hauser in 1883 was among the first clearly to point out histologically the transition of ulceration into carcinomatous proliferation. Since then various authors have differed widely concerning the frequency of this transition. Haberlen estimated $7 \%$ of cases occurring in this manner, Miculicz $7 \%$, Lebert $9 \%$, Rosenheim $6 \%$, Fenwick $3 \%$, Osler $2.6 \%$, while Moynihan estimates it at $60 \%$, William Mayo $54 \%$, Graham $62 \%$, and Wilson and MacCarty $71 \%$. It is difficult to reconcile the great diversity of opinion of the various writers. While it is generally admitted that carcinoma of the stomach usually develops without presenting a previous history of prolonged gastric disturbance, it has frequently been maintained that this does not militate against the theory of the development of carcinoma upon: the base of an occult ulcer, for Brinton has demonstrated the presence of gastric ulcer in about $5 \%$ of individuals, dying of diseases of all kinds.

Paterson has recently discussed this subject anew, and while he does not deny the possibility of a transformation of ulcer into cancer, he is doubtful as to the great frequency of this transition. He offers both clinical and pathological evidence in support of this view. In his clinical evidence he points out, that notwithstanding the fact that certain patients affected with carcinoma give a history of gastric disturbances lasting many years, this does not in any way indicate that these symptoms are due to ulceration; and furthermore, the fact that the patient has a history of gastric disturbance of long duration is not necessarily at variance with our views concerning the growth of cancers, for

* Presented at the Meeting of the American Gastro-Enterological Association, at Washington, May 5, 1913. 